\title{
Estimating the irradiance spectrum from measurements in a limited number of spectral bands
}

\author{
E.J. MILTON and E.M. ROLLIN
}

School of Geography, University of Southampton, Highfield, Southampton, SO17 1BJ, U.K.

\begin{abstract}
Accurate measurement and characterisation of fluctuations in the irradiance environment is important for many areas of optical remote sensing. This paper describes a method of estimating spectral irradiance over the region $400-1000 \mathrm{~nm}$ from the radiance of a calibrated reference panel, measured in four narrow spectral bands (FWHM approx.10 nm). The reproducibility of the method was found to have an average root mean squared error of approximately $30 \mathrm{mWm}^{-2} \mathrm{~nm}^{-1}$ over the region $400 \mathrm{~nm}$ to $1000 \mathrm{~nm}$ when applied to spectra covering a range of clear sky conditions typical of mid-latitude temperate regions.
\end{abstract}

Keywords: spectral irradiance, field spectroscopy, atmosphere, methodology, calibration. 


\section{Introduction}

Accurate spectral reflectance measurements from the field environment are needed for many purposes including vicarious calibration of satellite sensors (Slater et al. 1987), atmospheric correction (Moran et al. 2001), and to provide data with which to develop and test surface reflectance models (Kimes and Deering 1992). Field spectroradiometers are generally used to collect such data and the technique of field spectroscopy is well-established for this purpose (Milton 1987). The most common method used in field spectroscopy is referred to in this paper as 'single-beam' and involves sequential measurements of the spectral radiance from the target of interest followed by that from a calibrated reference panel. The directional/anisotropic hemispherical reflectance factor (Gu and Guyot, 1993), $R\left(0^{\circ} / h^{*}\right)$ is then calculated as:

$$
R\left(0^{\circ} / h^{*}\right)_{\lambda}=\left(\frac{L_{\lambda}}{L P_{\lambda}}\right) R p\left(0^{\circ} / h^{*}\right)_{\lambda}
$$

Equation 1

In which $L_{\lambda}$ is the flux from the surface, $L P_{\lambda}$ is the flux from the panel, and $R p\left(0^{\circ} / h^{*}\right)_{\lambda}$ is the directional/anisotropic hemispherical reflectance of the panel, measured in the same view geometry and under the same illumination conditions. $R\left(0^{\circ} / h^{*}\right)_{\lambda}$ is only an approximation of the true bidirectional reflectance factor of the surface as it depends upon the field-of-view of the instrument and the hazyness of the sky. This can be approximated by the diffuse-to-global ratio $\left(D G_{\lambda}\right)$ defined here as the ratio between the incident flux with the Sun obscured and the full hemispherical irradiance. $R\left(0^{\circ} / h^{*}\right)_{\lambda}$ also varies with solar zenith angle and possibly solar azimuth angle if the surface is spatially non-uniform.

The reproducibility of field spectral measurements can be greatly enhanced by using a dual-beam method in which the target and reference panel are measured simultaneously (Duggin and Cunia 1983). Gu et al. (1992) have estimated the total measurement error of a multiband radiometer operating in this configuration to be around $\pm 1.5 \%$. Despite these advantages, the dual-beam method is rarely adopted due to the cost of the additional spectroradiometer required and the need to derive and maintain the intercalibration between the two spectroradiometers (Anderson et al. 2005).

The spectrum of incident global irradiance is dominated by the direct beam which is primarily a function of the solar spectrum, modified by absorption and scattering by atmospheric gases, water vapour and aerosols. There is a high degree of redundancy in high spectral resolution measurements of irradiance, partly because the measuring devices commonly used have spectral bandwidths broader than the spectral sampling interval, but mainly because strong autocorrelation exists between irradiance at specific wavelengths. The basic premise of this paper is that the spectral irradiance distribution changes in a systematic way over the restricted range of sky conditions under which field spectra are measured. If this is true, then it should be possible to recreate the complete irradiance spectrum from measurements in a relatively few narrow bands, thus, avoiding the need for an expensive second spectroradiometer. Instead, a much simpler multiband instrument could be used to 
predict the spectral irradiance at exactly the same instant that the main spectroradiometer measures the target spectrum. An intercalibration procedure would still be necessary, but this would be easier to achieve and less susceptible to drift under field conditions because the temperature dependence of the small number of photodiodes in a multiband radiometer is easier to characterise than that of the large numbers of photodiodes in the linear array sensors commonly used in modern spectroradiometers. Richardson (1981) addressed the same problem as it affected data from a simple two-band radiometer and demonstrated that broadband measurements from a solarimeter could be used to predict the radiance of a reference panel in red and near infra-red wavelengths. This paper extends this concept to spectroradiometric data and to the mid-latitude temperate environment.

\section{Quality criteria for field reflectance measurements}

Three criteria may be used to assess the quality of spectral reflectance measurements made in the field: their traceability, repeatability and reproducibility (Fox, 2001). Traceability is the outcome of an unbroken chain of comparisons, each with stated uncertainty, which link the field measurement to a recognised international standard. It is dependent on the reference panel used and on the stability and linearity of the spectroradiometer in the field environment. Reference panels designed for this purpose are generally supplied with a calibration certificate traceable to an international standard. However, this is often only for a single geometry of illumination and view, and the conditions of measurement by the standards laboratory often do not match those found in the field, especially regarding the spectral distribution of the light source and the angular distribution of direct and diffuse flux. This point has been discussed further by Gu and Guyot (1993) and Rollin et al. (2000). Traceability is more difficult to achieve if it is necessary to measure radiance in the field, as opposed to reflectance, especially if the instrument is affected by temperature changes (Duggin and Philipson 1982, Jackson and Robinson 1985).

'Repeatability' in this context refers to the closeness of the agreement between the results of successive measurements of the same measurand carried out under the same conditions of measurement. It is a property of the spectroradiometer and is affected by noise sources and instability in the electronic and optical systems within the instrument. Modern field spectroradiometers generally have high levels of repeatability, as shown by repeated measurements of a highly stable uniform source, for example, an integrating sphere. Anderson (2005) tested two GER1500 ${ }^{\mathrm{TM}}$ spectroradiometers and found they each had a noise-equivalent change in radiance of better than 0.002 $\mathrm{mWsr}^{-1} \mathrm{~m}^{-2} \mathrm{~nm}^{-1}$ over the range 400-1000 nm. Ideally, such data would be measured with the instrument viewing a source having a similar intensity and spectral distribution to the Sun, but this is rarely possible.

This paper concerns the third criterion of data quality: the reproducibility of field spectral measurements, which refers to the closeness of the agreement between the results of successive measurements of the same surface made in the field environment. 'Reproducibility' in this context embraces both the repeatability of the instrument and the uncertainty introduced by the irradiation environment in which the measurements are made. Several factors conspire to reduce the accuracy of field spectra compared with those measured in the laboratory. These include the configuration of the apparatus used (Milton 1987), the proximity of adjacent objects (Kimes et al. 1983), and most importantly, the time delay between measurement of the target surface and the reflectance panel 
(Duggin and Cunia 1983, Milton et al. 1995). Although this can be kept to a minimum by good technique in the field, experience suggests that even under ideal conditions, sub-visual patches of water vapour passing through the direct solar beam lead to a coefficient of variation of around $1 \%$ in sequences of irradiance measurements. Most of the time, and in most environments around the world, the sky conditions are much more variable and the level of uncertainty is much higher. For example, an uncertainty of 5-10\% in ‘clear-sky’ irradiance has been reported by Duggin and Philipson (1982).

\section{Methods}

The basic principle of the method has been demonstrated in earlier studies in which spectral irradiance measurements at a limited number of wavelengths have been extracted from high resolution irradiance spectra and used to regenerate the complete irradiance spectra to a high level of precision (Milton and Goetz 1997, Milton et al. 2000, Rollin and Milton 2003). This paper describes the important next step of applying this method to the situation in which data from a mutiband radiometer are used to generate an irradiance spectrum which is then compared against that measured at exactly the same time using an independent spectroradiometer.

A Spectron SE590 ${ }^{\mathrm{TM}}$ spectroradiometer with a cosine-corrected receptor was used to measure irradiance over the range 400 - $1100 \mathrm{~nm}$ (FWHM bandwidth approximately 10nm). The sensor head was fixed pointing vertically upwards to measure the total sky irradiance. Diffuse irradiance was measured by using a small black circular disk mounted on the end of a long pole to obscure the direct solar beam. The SE590 with cosine-corrected receptor was calibrated to irradiance in the NERC EPFS ${ }^{1}$ laboratory using an Optronics Laboratory 1000 W FEL lamp calibrated by the UK National Physical Laboratory (NPL). The angular sensitivity of the SE590 irradiance receptor was measured in the NERC EPFS laboratory and found to conform closely to a cosine response over zenith illumination angles from $0^{\circ}$ to $60^{\circ}$.

A multiband radiometer was constructed to measure radiance in seven spectral bands. The instrument comprises seven identical photodiodes, each located within a baffled tube to provide a nominal fieldof-view of $5^{\circ}$ (full angle). The bands were chosen in relation to features of the irradiance spectrum and its variability, whilst also making use of standard commercially available interference filters to minimise the cost of the instrument. The filters used were narrow bandpass interference filters sourced from Edmund Optics Ltd. and have a nominal bandwidth of $10 \mathrm{~nm}$ (FWHM), centred on $430 \mathrm{~nm}$, $500 \mathrm{~nm}, 780 \mathrm{~nm}, 820 \mathrm{~nm}, 830 \mathrm{~nm}, 880 \mathrm{~nm}$ and $950 \mathrm{~nm}$. The band at $430 \mathrm{~nm}$ was located so as to anchor the short wavelength region while the band at $500 \mathrm{~nm}$ was located close to the peak spectral irradiance and those at $780 \mathrm{~nm}$ and $880 \mathrm{~nm}$ were chosen to capture the slope of the irradiance continuum in the near infra-red. The bands at $820 \mathrm{~nm}, 830 \mathrm{~nm}$ and $950 \mathrm{~nm}$ were located within and on the shoulders of water absorption bands. The multiband radiometer was calibrated to radiance using a Hoffman LS-64-8D ${ }^{\mathrm{TM}}$ integrating sphere traceable to NPL and the bidirectional reflectance of the Spectralon panel was also determined by NPL. In field use, the raw data from the multiband radiometer are timestamped and calibrated to radiance before being converted to irradiance by correcting for the bidirectional reflectance of the Spectralon panel.

\footnotetext{
${ }^{1}$ UK Natural Environment Research Council Equipment Pool for Field Spectroscopy.
} 
A series of field experiments were conducted during Spring and Summer 2003 to acquire paired data sets from the SE590 and the multiband radiometer. Spectral irradiance data were collected using the Spectron SE590 spectroradiometer which was operated manually so that spectra could be collected approximately every 30 seconds during measurement windows of 10 - 30 minutes spread over several hours. A signal from the spectroradiometer was used to trigger simultaneous measurements by the separate multiband radiometer positioned over a calibrated Spectralon reference panel. The aim of each experiment was to acquire data over a long period of time during which the sky remained clear and suitable for field spectroscopy. Irradiance changes during such periods are the result of systematic change in solar geometry and unpredictable change due to sub-visual patches of haze and water vapour. The changeable nature of the weather in the UK meant that it was very difficult to achieve a long series of measurements on any one date, and many attempts were curtailed as cloud cover increased, making conditions unsuitable. Three suitable data sets were obtained: one from a site in southern England collected between 09:30 - 13:15 GMT on $16^{\text {th }}$ April 2003, and two from a site in eastern England, the first collected between 09:13 - 13:10 GMT on 29 $9^{\text {th }}$ May 2003 and the second between 09:44 - 12:00 GMT on $16^{\text {th }}$ June 2003. The sky condition during the first and last of these field experiments was more stable that than that on $29^{\text {th }}$ May, which was marked by several periods of irradiance variability caused by the passage of sub-visual clouds through the direct solar beam. This is reflected in the average diffuse-to-global ratios measured at $550 \mathrm{~nm}$ on each occasion: 0.21 (st. dev. 0.003 ) on $16^{\text {th }}$ April, 0.35 (st. dev. 0.010) on $16^{\text {th }}$ June, and 0.53 (st. dev. 0.056) on $29^{\text {th }}$ May.

The three data sets were organised into a training data set and an independent validation data set. The training data set comprised 111 spectra from the measurements made on $16^{\text {th }}$ April 2003 and $16^{\text {th }}$ June 2003 (Figure 1). These two sets were combined in order to cover a wide range of solar zenith angles (29.0 to 51.5 degrees). The validation data set comprised 46 spectra from the measurements made on $29^{\text {th }}$ May 2003, which covered a range of solar zenith angles from 30.76 to 44.0 degrees (Figure 2). 


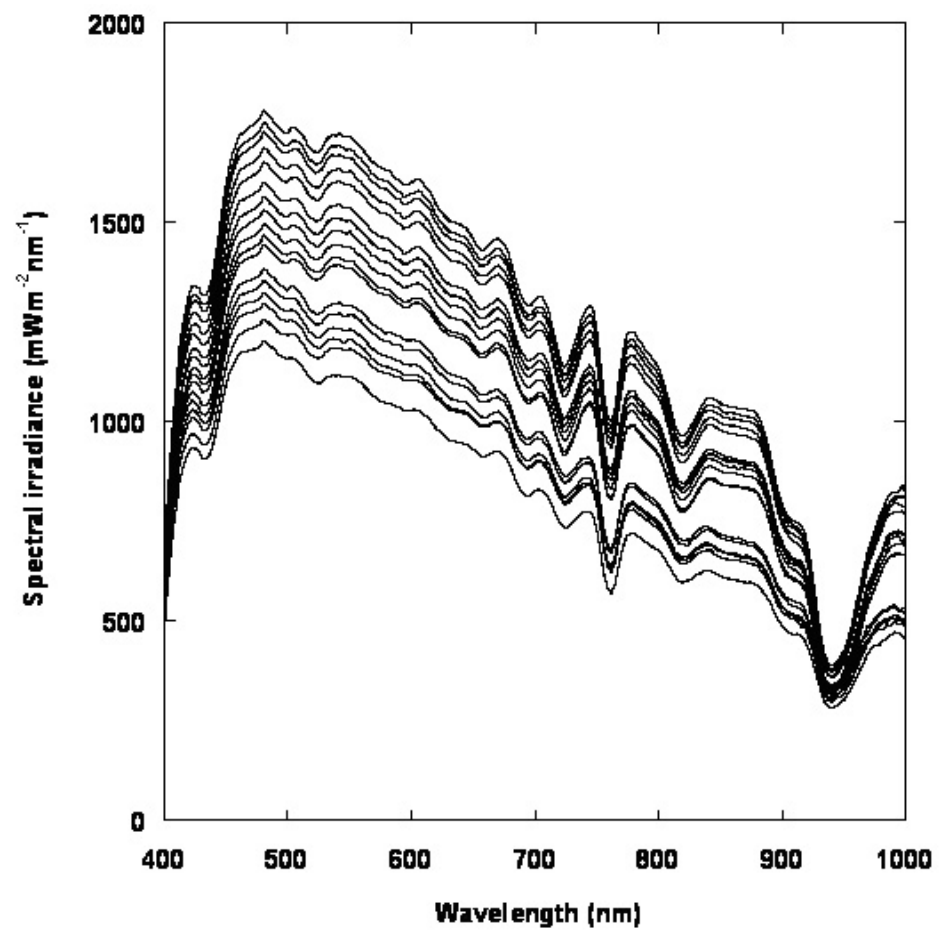

Figure 1. Eighteen representative spectra, chosen from the 41 spectra measured on $16^{\text {th }}$ April 2003 and the 70 spectra measured on $16^{\text {th }}$ June 2003 to show the range of the training data.

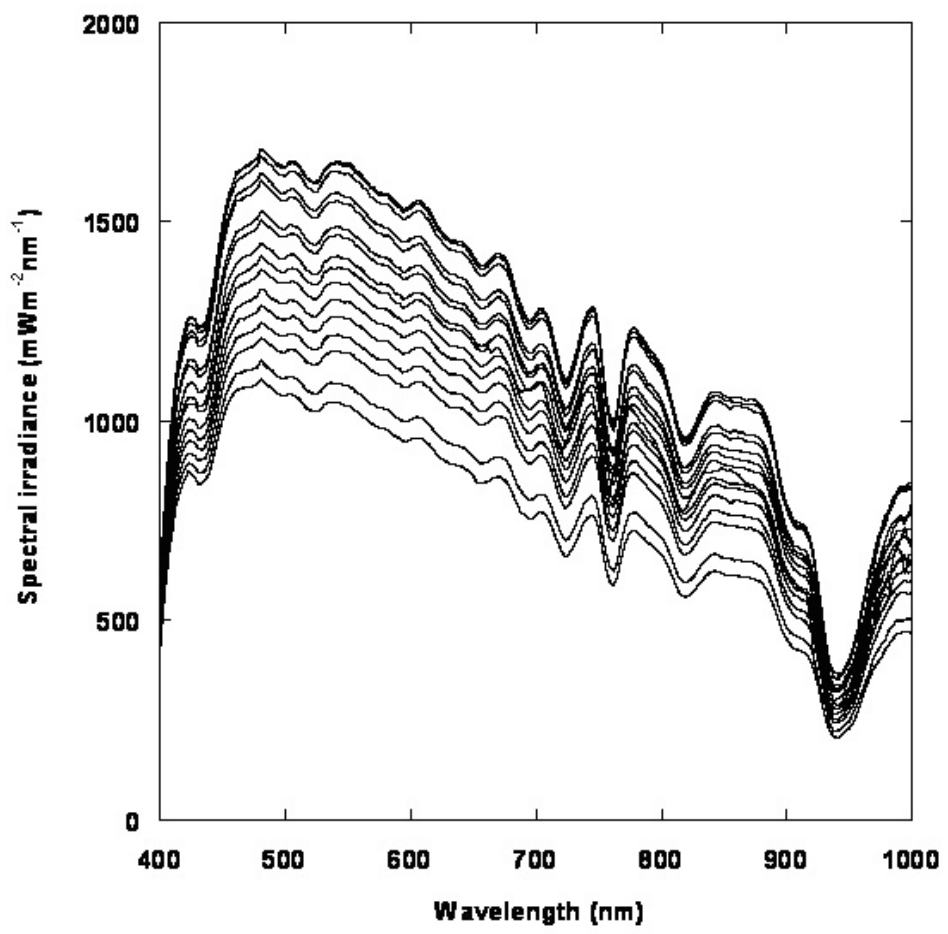

Figure 2. Sixteen representative spectra from the validation data set, in total comprising 46 spectra measured on $29^{\text {th }}$ May 2003. 
Figure 3 shows the percentage coefficient of variation of irradiance for the training data set plotted against wavelength and shows a consistent positive trend with increasing wavelength, except for a localised region of reduced variability around the water absorption band at $940 \mathrm{~nm}$.

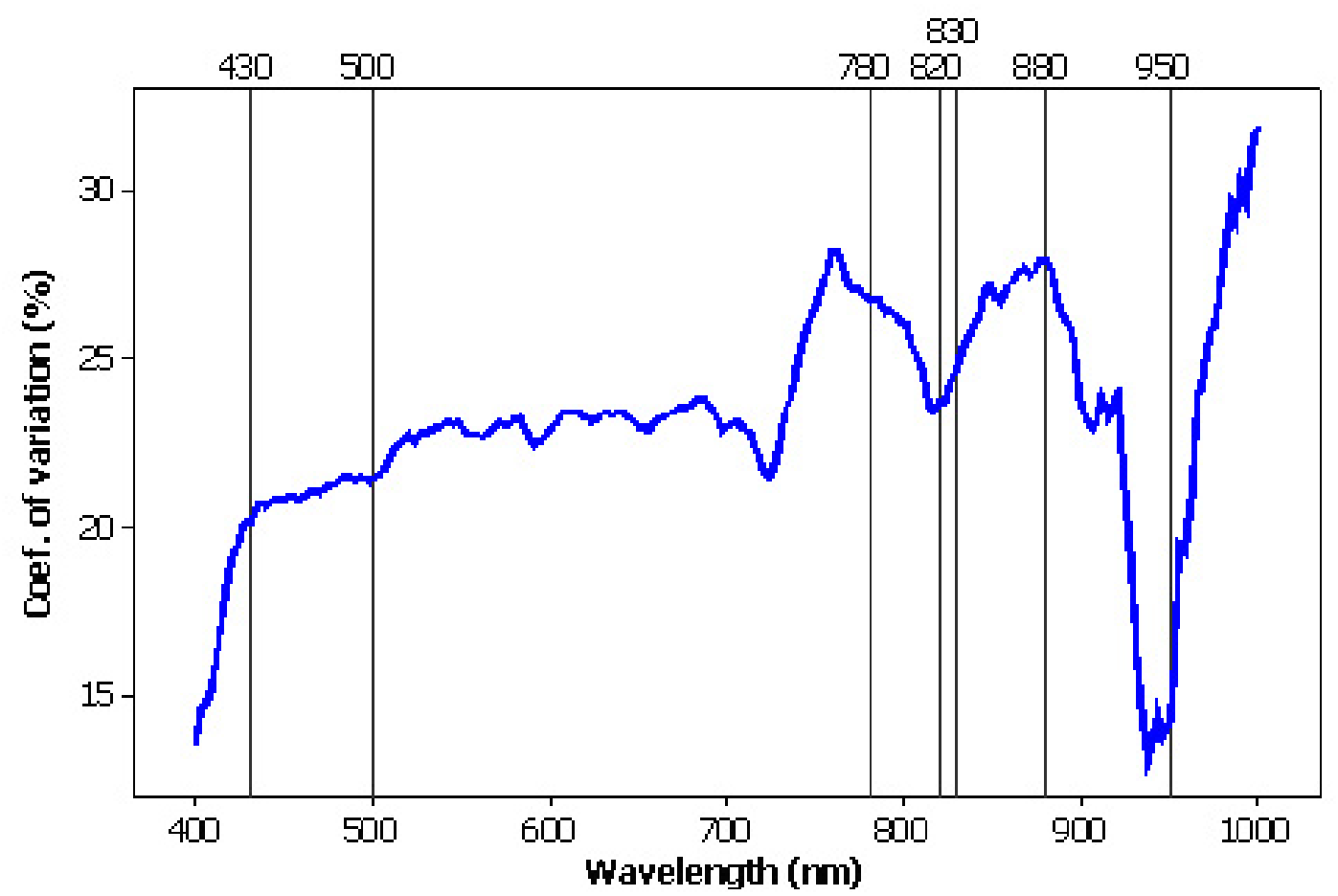

Figure 3. Coefficient of variation of the irradiance spectra in the training set. The centre wavelengths of the multiband radiometer bands are also shown.

\section{Results}

Table 1 shows the Pearson product-moment correlation coefficient between the seven bands in the training set. As expected, all the bands are highly inter-correlated $(\mathrm{p}<0.05)$. However, there is some independent information about the irradiance spectrum contained in most of the bands. Stepwise multiple regression was applied to the training set to relate each of the 204 bands measured by theSE590 spectroradiometer to the irradiance data in the seven bands. 
Table 1. Pearson product-moment correlation coefficients between the seven bands in the training data set acquired with the multiband instrument (all significant $\alpha=0.05, \mathrm{n}=111$ ).

\begin{tabular}{|l|c|c|c|c|c|c|}
\hline & $430 \mathrm{~nm}$ & $500 \mathrm{~nm}$ & $780 \mathrm{~nm}$ & $820 \mathrm{~nm}$ & $830 \mathrm{~nm}$ & $880 \mathrm{~nm}$ \\
\hline $500 \mathrm{~nm}$ & 0.998 & & & & & \\
\hline $780 \mathrm{~nm}$ & 0.977 & 0.988 & & & & \\
\hline $820 \mathrm{~nm}$ & 0.988 & 0.995 & 0.997 & & & \\
\hline $830 \mathrm{~nm}$ & 0.985 & 0.993 & 0.999 & 1.000 & & \\
\hline $880 \mathrm{~nm}$ & 0.976 & 0.986 & 1.000 & 0.997 & 0.999 & \\
\hline $950 \mathrm{~nm}$ & 0.952 & 0.936 & 0.889 & 0.921 & 0.912 & 0.891 \\
\hline
\end{tabular}

A total of 204 regression equations were calculated, one for each wavelength of the spectroradiometer, excluding those below $400 \mathrm{~nm}$ and above $1000 \mathrm{~nm}$ which had low signal-to-noise ratio. Examples of the regression equations produced are shown in Table 2. In most cases as few as two or three predictor bands were sufficient to explain most of the variation in spectral irradiance $\left(R^{2}>0.99\right)$, although the predictor bands selected varied with wavelength as would be expected.

Table 2. Example results from the stepwise multiple regression analysis.

Figures in parentheses are the predictor bands. All coefficients are significant at $\alpha=0.05$.

\begin{tabular}{|c|c|c|c|c|}
\hline $\begin{array}{c}\text { Response } \\
\text { variable }\end{array}$ & $\mathrm{R}^{2}$ & $\begin{array}{c}\text { Constant } \\
\text { term }\end{array}$ & Regression model & $\begin{array}{l}\text { Number } \\
\text { of steps }\end{array}$ \\
\hline $400 \mathrm{~nm}$ & $0.973^{*}$ & 107.1 & $\begin{array}{l}0.4106(430)-0.885(950)- \\
1.423(880)+1.77(830)\end{array}$ & 4 \\
\hline $450 \mathrm{~nm}$ & 0.998 & 144.7 & $0.6478(500)-0.751(950)+0.480(430)$ & 3 \\
\hline $500 \mathrm{~nm}$ & 0.998 & 125.3 & $1.125(500)-0.841(950)$ & 2 \\
\hline $550 \mathrm{~nm}$ & 0.998 & 125.9 & $0.3334(780)+\odot .896(50 \odot)-0.895(950)$ & 3 \\
\hline $600 \mathrm{~nm}$ & 0.998 & 113.5 & $0.3941(780)+\odot .741(500)-\odot .678(950)$ & 3 \\
\hline $650 \mathrm{~nm}$ & 0.998 & 123.6 & $1.3473(780)-0.75(880)+0.516(430)$ & 4 \\
\hline $700 \mathrm{~nm}$ & 0.998 & 129.4 & $0.475(430)-1.227(950)+1.099(820)$ & 7 \\
\hline $750 \mathrm{~nm}$ & 0.998 & 109.95 & $0.976(780)-0.764(950)+0.183(430)$ & 3 \\
\hline $800 \mathrm{~nm}$ & 0.998 & 126.93 & $0.944(780)-0.402(950)$ & 2 \\
\hline $850 \mathrm{~nm}$ & 0.998 & 111.26 & $1.486(780)-0.929(820)$ & 2 \\
\hline $900 \mathrm{~nm}$ & 0.997 & 86.92 & $0.5726(780)$ & 1 \\
\hline $950 \mathrm{~nm}$ & $0.974^{\star}$ & 58.4 & $0.6(950)+0.0602(500)$ & 2 \\
\hline $1000 \mathrm{~nm}$ & 0.997 & 50.72 & $1.8052(780)-1.495(820)$ & 2 \\
\hline
\end{tabular}

* $\mathrm{R}^{2}$ never exceeded 0.990

A potential problem with this approach concerns the high correlation between the predictor variables. Multicollinearity can create regression relationships that are very specific to the data set from which they were derived, so it would be unwise to apply the same coefficients to other data sets without first testing their suitability. However, the predictor bands selected appear plausible, placing greater emphasis on shorter wavelengths $(430 \mathrm{~nm}$ and $500 \mathrm{~nm}$ ) when predicting the visible region, and on 
those wavelengths associated with the shape of water absorption features (780 nm and $950 \mathrm{~nm}$ ) when predicting the near infra-red region. The most commonly selected predictor band was $950 \mathrm{~nm}$, followed by $780 \mathrm{~nm}$. The next most important predictor bands were $430 \mathrm{~nm}$ and $500 \mathrm{~nm}$, both chosen far more often than $820 \mathrm{~nm}, 880 \mathrm{~nm}$ and $830 \mathrm{~nm}$. In order to investigate this further, the stepwise multiple regression was repeated based on the four most frequently selected predictor bands and example results from this can be seen in Table 3 . The very high $\mathrm{R}^{2}$ values suggest that measurements in these four bands are sufficient to recreate the irradiance spectrum almost as well as the full set of seven predictor bands.

Figure 4 shows the Mean Bias Error (MBE) of the validation data set, calculated as the average difference between the irradiance predicted by the regression model at each wavelength and that measured by the spectroradiometer, for both the full set of seven predictor bands and for the four most commonly selected bands ( $430 \mathrm{~nm}, 500 \mathrm{~nm}, 780 \mathrm{~nm}$ and $950 \mathrm{~nm}$ ). The size of the MBE is roughly the same for both methods, but the results using four predictor bands show more consistency with wavelength than those using the full set of seven bands. Overall, the MBE is around $30-40 \mathrm{mWm}^{-}$ ${ }^{2} \mathrm{~nm}^{-1}$ in the visible region and $20-30 \mathrm{mWm}^{-2} \mathrm{~nm}^{-1}$ in the near infra-red, and it is positive for all wavelengths greater than $420 \mathrm{~nm}$. Better intercalibration between the spectroradiometer and the multiband radiometer would be expected to reduce the size of the bias error.

Table 3. Example results from the stepwise multiple regression analysis based on a subset of four predictor bands : $950 \mathrm{~nm}, 780 \mathrm{~nm}, 500 \mathrm{~nm}$ and $430 \mathrm{~nm}$. Figures in parentheses are the predictor bands.

All coefficients are significant at $\alpha=0.05$.

\begin{tabular}{|c|c|c|c|c|}
\hline $\begin{array}{l}\text { Response } \\
\text { variable }\end{array}$ & $\mathrm{R}^{2}$ & $\begin{array}{l}\text { Constant } \\
\text { term }\end{array}$ & Regression model & $\begin{array}{l}\text { Number } \\
\text { of steps }\end{array}$ \\
\hline $400 \mathrm{~nm}$ & 0.969 & 114.4 & $\begin{array}{l}-0.2977(430)-0.254(950)-0.282(780)+ \\
0.78(50 \odot)\end{array}$ & 4 \\
\hline $450 \mathrm{~nm}$ & 0.998 & 144.7 & $0.6478(500)-0.751(950)+\odot .48(430)$ & 3 \\
\hline $500 \mathrm{~nm}$ & 0.998 & 163.54 & $\begin{array}{l}\odot .5627(50 \odot)-0.847(950)+0.186(780)+ \\
\odot .53(430)\end{array}$ & 4 \\
\hline $550 \mathrm{~nm}$ & 0.998 & 125.9 & $0.3334(780)+0.896(500)-0.895(950)$ & 3 \\
\hline $600 \mathrm{~nm}$ & 0.998 & 113.5 & $0.3941(780)+0.741(500)-0.678(950)$ & 3 \\
\hline $650 \mathrm{~nm}$ & 0.998 & 132.3 & $0.512(780)+0.561(500)-0.656(950)$ & 3 \\
\hline $700 \mathrm{~nm}$ & 0.998 & 126.4 & $0.5402(780)+0.426(500)-0.538(950)$ & 3 \\
\hline $750 \mathrm{~nm}$ & 0.998 & 109.95 & $0.976(780)-0.764(950)+0.183(430)$ & 3 \\
\hline $800 \mathrm{~nm}$ & 0.998 & 126.93 & $0.944(780)-0.402(950)$ & 2 \\
\hline $850 \mathrm{~nm}$ & 0.998 & 105.01 & $0.9441(780)-0.527(950)$ & 2 \\
\hline $900 \mathrm{~nm}$ & 0.997 & 86.92 & $0.5726(780)$ & 1 \\
\hline $950 \mathrm{~nm}$ & $0.974^{*}$ & 58.4 & $0.6(950)+0.0602(50 \odot)$ & 2 \\
\hline $1000 \mathrm{~nm}$ & 0.997 & 39.06 & $0.9317(780)-0.84(950)$ & 2 \\
\hline
\end{tabular}

$* \mathrm{R}^{2}$ never exceeded 0.990 


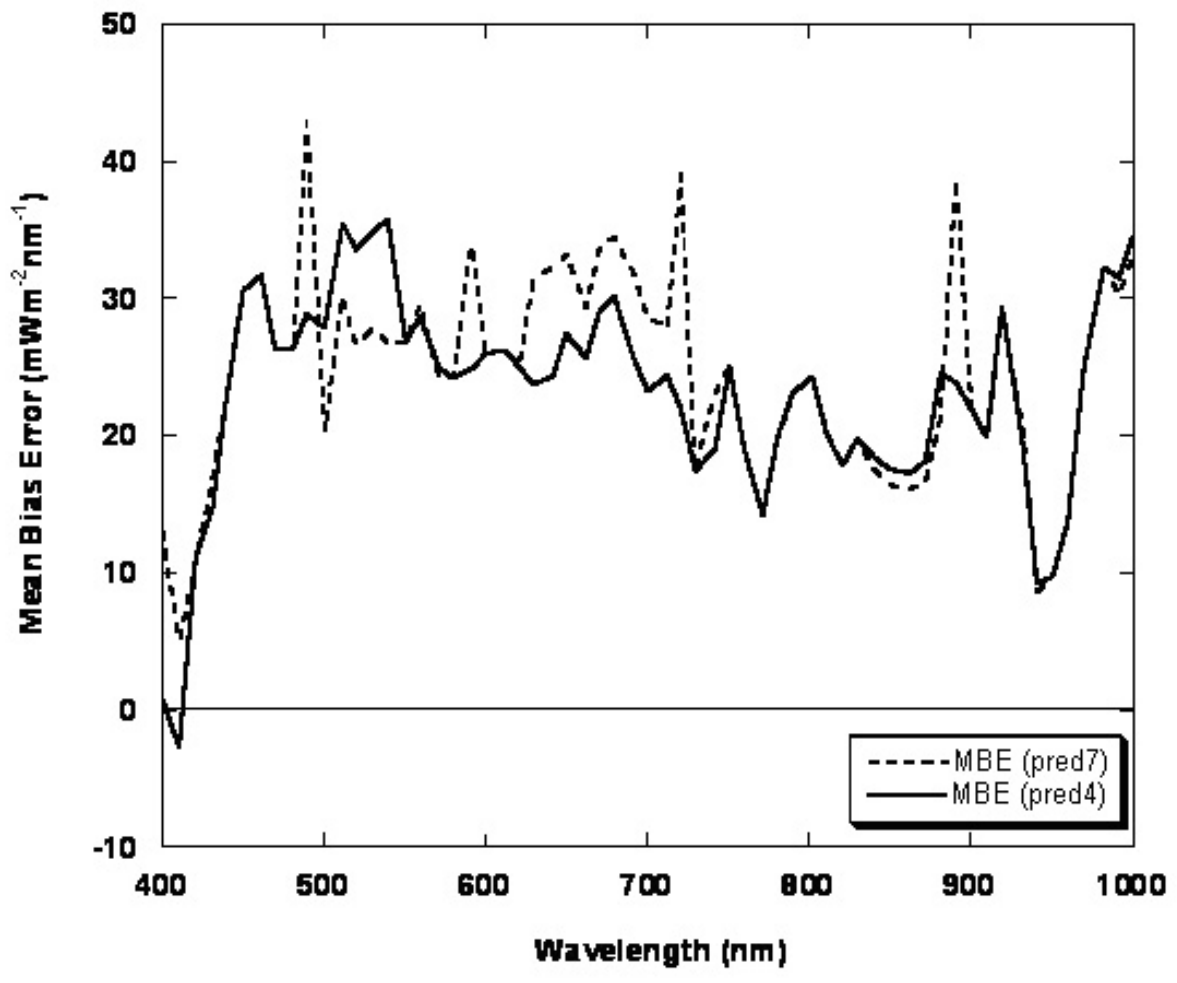

Figure 4. Mean Bias Error (MBE) of the validation data set expressed as (Predicted irradiance) (Observed irradiance) for the regression models based on all 7 predictor bands (dashed line) and those based on 4 predictor bands (solid line).

The root mean squared error (rmse) of irradiance measured from the validation data set is shown in Figure 5. The error is approximately $30 \mathrm{mWm}^{-2} \mathrm{~nm}^{-1}$ in the visible region, relative to a typical irradiance value of over $1000 \mathrm{mWm}^{-2} \mathrm{~nm}^{-1}$. The rmse is slightly less at longer wavelengths but is a greater proportion of the incident irradiance at these wavelengths. 


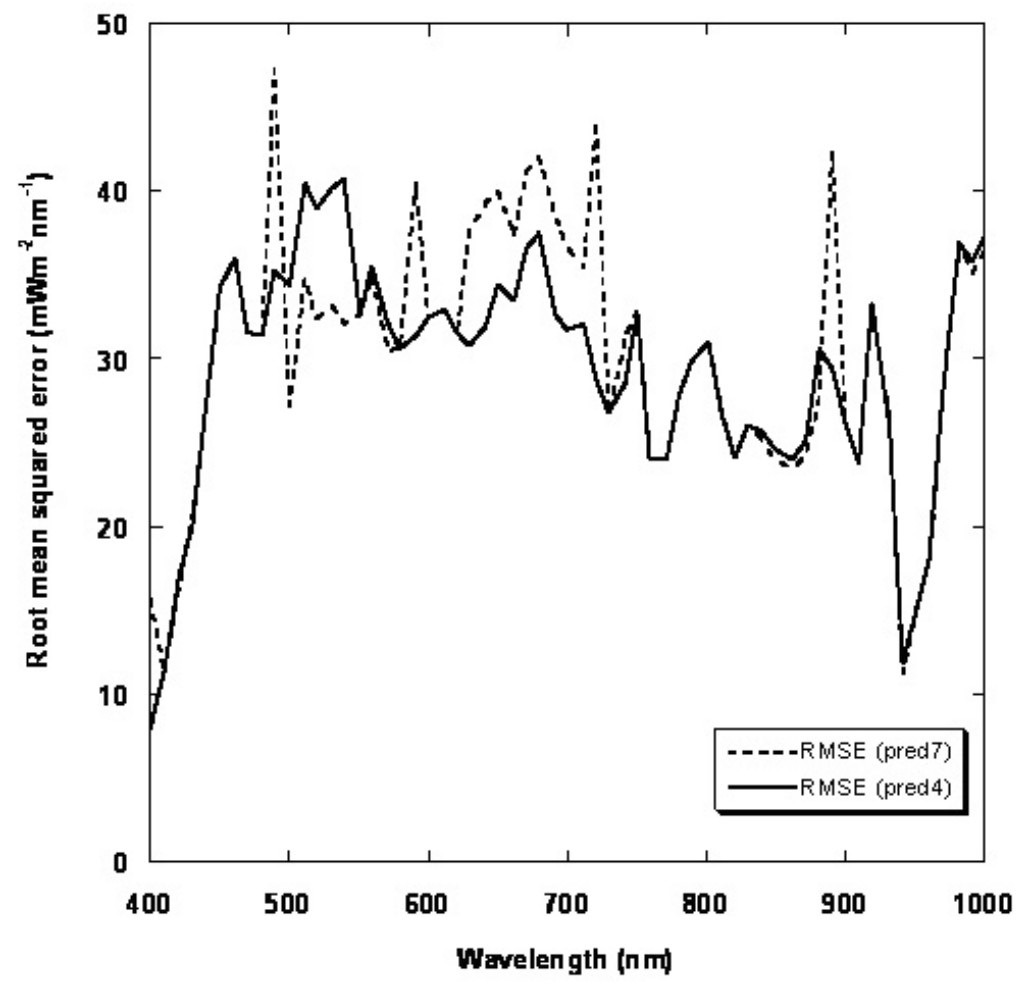

Figure 5. Root mean squared error of the validation data set for the regression models based on all seven predictor bands (dashed line) and those based on four predictor bands (solid line).

\section{Evaluation of the results}

The experiment has shown that it is possible to generate an irradiance spectrum over the region 400 $1000 \mathrm{~nm}$ from measurements of the radiance of a reference panel in four $10 \mathrm{~nm}$ wide bands centred on $430 \mathrm{~nm}, 500 \mathrm{~nm}, 780 \mathrm{~nm}$ and $950 \mathrm{~nm}$. The reproducibility of such spectra, as represented by the rmse was approximately $\pm 30 \mathrm{mWm}^{-2} \mathrm{~nm}^{-1}$ under conditions typical of 'clear skies' in summer in the UK. Whether this is an improvement on the conventional method, in which sequential measurements are made of the target surface and a reference panel, depends on the error introduced by the time delay between these two measurements. To investigate this further, the validation data set was screened to identify irradiance spectra that had been collected less than 60 seconds apart. This time interval was chosen as typical of the single-beam sequential method of measuring spectral reflectance in the field. This resulted in eighteen irradiance spectra, with a median time interval of 23 seconds between successive spectra. The rmse of these spectra represents the error in irradiance which the sequential method would be subject to, assuming that 23 seconds is a reasonable estimate of the delay between measurement of the radiance of the target surface and that of the reference panel. The rmse of the closely spaced (in time) irradiance spectra may be compared with the rmse of the irradiance spectra generated from the multiband radiometer data, in which there is no time delay involved. Figure 6 shows that the rmse of the irradiance spectra generated using data from the multiband radiometer is about half that of those measured by the conventional single-beam sequential method. Although this is a significant result, it would be a mistake to infer from this that the proposed new method is twice as 
precise as the conventional single-beam, sequential method. The new method removes the uncertainty caused by the time delay between measurement of the target surface and the reference panel, but it introduces additional uncertainty through the need to intercalibrate the spectroradiometer and the multiband radiometer, and the requirement to maintain that calibration over time, as well as the error inherent in the regression models themselves. Progress in each of these areas will be critical in determining which is the most reproducible method of making field spectral measurements.

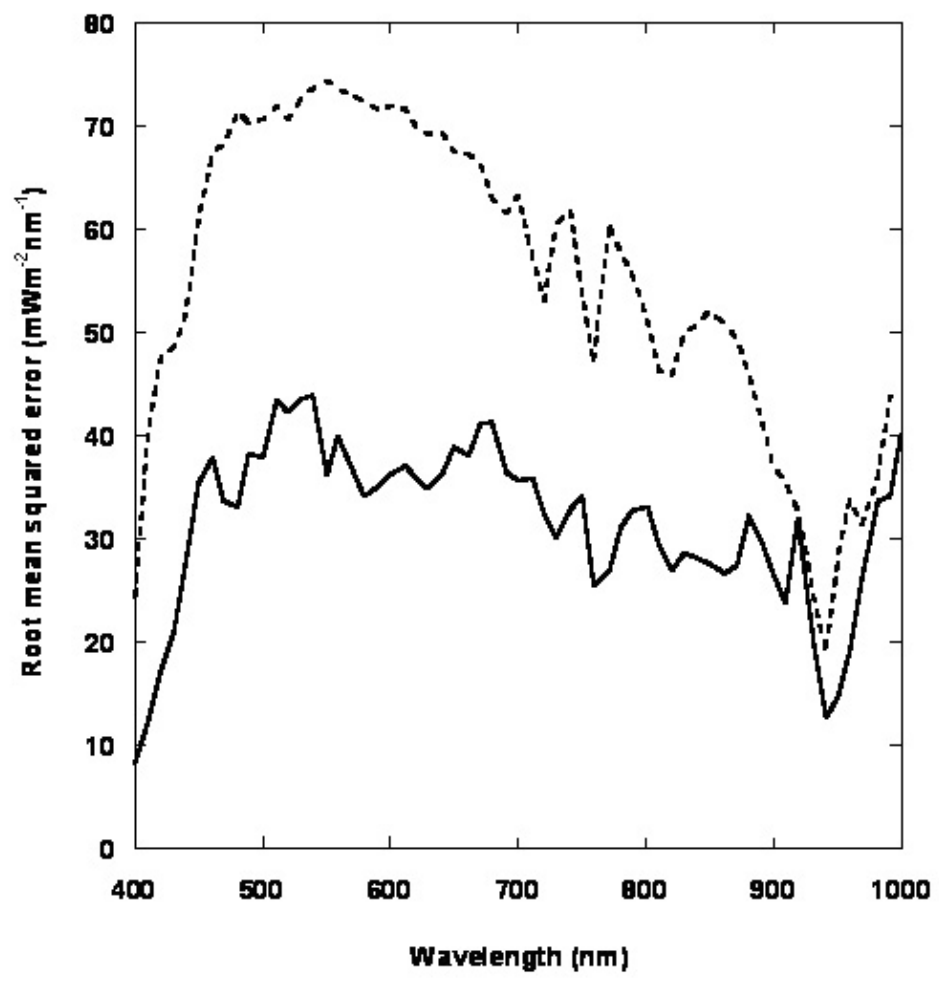

Figure 6. Root mean squared error of irradiance sampled at intervals of less than 60 seconds (median $=$ 23 seconds) (dashed line) compared with that estimated by the 4 predictor bands at the same time (solid line).

The final stage of evaluation of the method concerns the impact of such irradiance errors on a typical reflectance spectrum. A grass vegetation spectrum measured on $16^{\text {th }}$ April 2003 using a GER3700 spectroradiometer was used for this part of the study. Figure 7 shows the error in the grass reflectance spectrum which would result from a change in the irradiance at each wavelength by an amount equal to the rmse of the two methods. In both cases the error in reflectance increases with wavelength, but the error is consistently larger with the single-beam sequential method than with the simulated dual-beam method. The simulated dual-beam method will be most accurate when used with a highly reflective white reference panel, as any irradiance error will be a larger proportion of the measured signal if a grey reference panel is used. Grey panels are often used for single-beam sequential measurements as they are closer in reflectivity to most natural surfaces, but this is not necessary if a dedicated instrument is used to measure the spectral irradiance.

For the specific conditions encountered in this study, the reproducibility of single-beam sequential reflectance measurements under temperate latitude 'clear sky' conditions was around $\pm 7 \%$ of the 
measured reflectance value, whereas the reproducibility of the simulated dual-beam method was around $\pm 3 \%$ of the measured reflectance. Clearly, the simulation method was more unstable in the region around the $940 \mathrm{~nm}$ water absorption feature, but even here, the rmse was less than the conventional method.

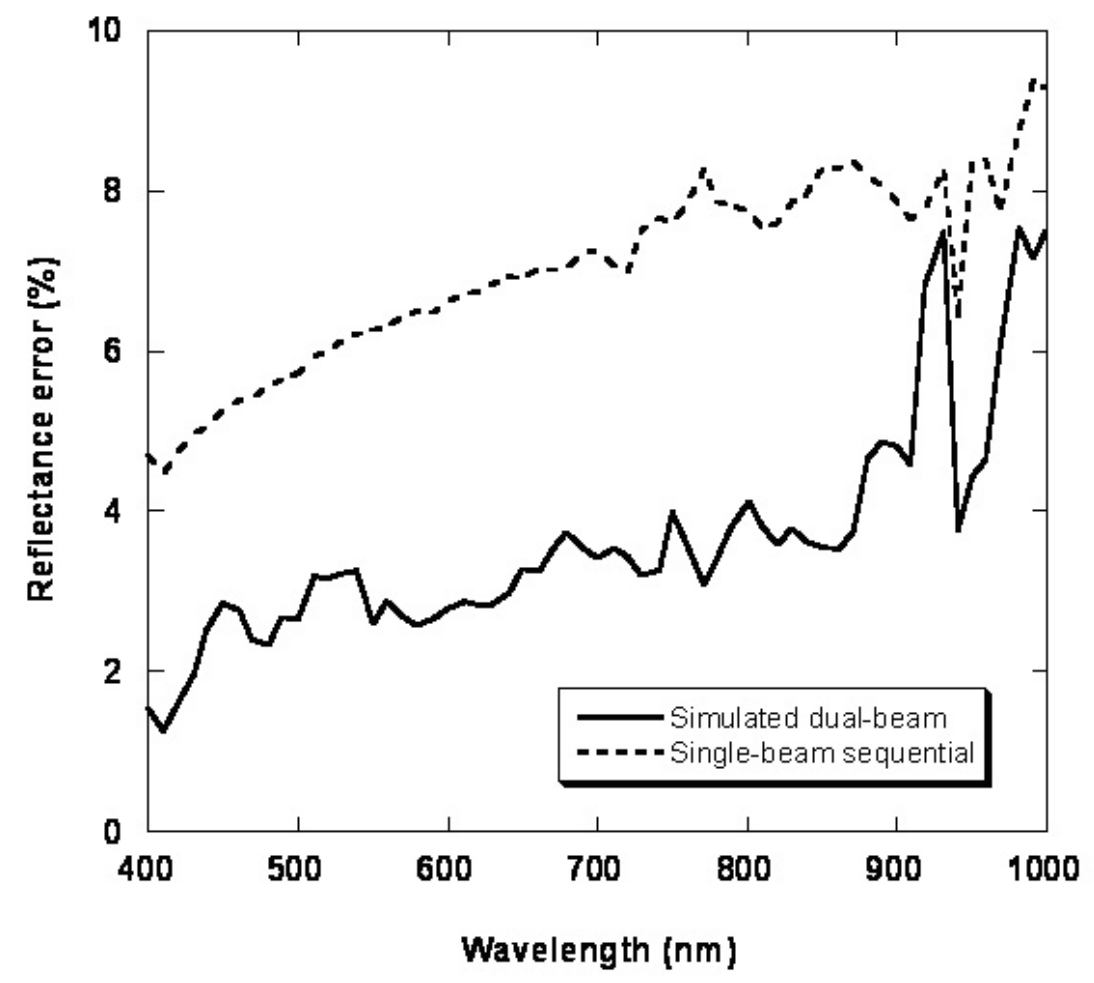

Figure 7. Comparison between the error of a green vegetation reflectance spectrum calculated using irradiance values varied by amounts equal to the rmse of the simulated dual-beam method (solid line) and the single-beam sequential method (broken line).

The results demonstrate the limited dimensionality of the irradiance spectrum associated with the sky conditions suitable for field spectroscopy, and this echoes the results that other researchers have found for reflectance spectra from soils and vegetation (e.g. Price 1994). This raises the question of just how few bands are necessary to recreate the irradiance spectrum to the level of accuracy and detail that is necessary for Earth observation puposes. The evidence presented in this paper suggests that four $10 \mathrm{~nm}$ wide bands are probably sufficient for most practical purposes. Indeed, it may be possible to recreate irradiance spectra from fewer than four bands, but that was not investigated in this study.

The simulated dual-beam method will be especially useful for measurement scenarios in which it is difficult to relocate the spectroradiometer from measuring the target surface to measuring the reference panel. For example, in many goniometer designs there is necessarily a delay of several minutes between target and panel measurements, leading to poor reproducibility. Estimating spectral irradiance by using a dedicated multiband radiometer triggered at exactly the same instant that the angular 
radiance data are measured would improve the reproducibility of goniometric measurements in the field situation.

The simulated dual-beam method also has potential to estimate the spectral irradiance in the shortwave infra-red (SWIR) region. SWIR spectroradiometers are very expensive and it is rarely possible to dedicate one simply to measuring irradiance. However, the physical mechanisms controlling the interactions between electromagnetic radiation and the atmosphere remain the same throughout the optical region, so it should be possible to use the method described to generate the SWIR irradiance spectrum from a measurements in a small number of bands in the visible and near infra-red region.

\section{Conclusion}

Dual-beam reflectance measurement is the most reproducible in the field environment, but this method is rarely used, primarily due to the cost of the additional high-performance field spectroradiometer. This paper has shown how a simple multiband radiometer may be used in place of the second spectroradiometer, and how the complete irradiance spectrum may be derived from measurements in a few narrow spectral bands. The method has been shown to work over a range of clear sky conditions and solar zenith angles typical of mid-latitude environments. The limit of applicability of the method remains to be established : it cannot be expected to account for intermittent clouds, for example, and one cannot expect a multiband instrument with $10 \mathrm{~nm}$ nominal bandwidth to retrieve fine spectral features in the irradiance spectrum. However, the method provides a practical solution to the problem of unpredictable changes in irradiance during field spectral measurements, and offers the possibility of improving the quality of single-beam reflectance spectra at relatively low cost.

\section{Acknowledgements}

The authors gratefully acknowledge the help and technical expertise of Bill Damon, who designed and constructed several prototypes of the multiband radiometer and, together with Karen Anderson, SallyBeth Kelday and Dominic Lawrance, assisted with data collection. Peter Atkinson provided helpful comments on the paper, and the support of the UK Natural Environment Research Council is acknowledged for access to the spectroradiometers and calibration facilities. The development of the multiband radiometer was funded by the GeoData Institute, University of Southampton. 


\section{References}

Anderson, K. (2005). Temporal variability in calibration target reflectance: methods, models and applications. Unpublished PhD Thesis, University of Southampton, UK, 381pp.

Anderson, K., Milton, E. J. and Rollin, E. M., in press. Calibration of dual-beam spectroradiometric data. International Journal of Remote Sensing.

Duggin, M. J. and Cunia, T., 1983. Ground reflectance measurement techniques: a comparison. Applied Optics 22, 3771-3777.

Duggin, M. J. and Philipson, W. R., 1982. Field measurement of reflectance: some major considerations. Applied Optics 21, 2833-2840.

Fox, N. P., 2001. Traceability to SI for EO measurements. CEOS WGCV Cal/Val Newsletter. 9, 1-9.

Gu, X. F., Guyot, G. and Verbrugghe, M., 1992. Evaluation of measurement errors in ground surface reflectance for satellite calibration. International Journal of Remote Sensing 13, 2531-2546.

Gu, X. F. and Guyot, G., 1993. Effect of diffuse irradiance on the reflectance factor of reference panels under field conditions. Remote Sensing of Environment 45, 249-260.

Jackson, R. D. and Robinson, B. F., 1985. Field evaluation of the temperature stability of a multispectral radiometer. Remote Sensing of Environment 17, 103-108.

Kimes, D. S., Kirchner, J. A. and Newcomb, W. W., 1983. Spectral radiance errors in remote sensing ground studies due to nearby objects. Applied Optics 22, 8-10.

Kimes, D. S. and Deering, D. W., 1992. Remote Sensing of Surface Hemispherical Reflectance (Albedo) Using Pointable Multispectral Imaging Spectroradiometers. Remote Sensing of Environment 39, 85-94.

Milton, E. J., 1987. Principles of field spectroscopy. International Journal of Remote Sensing 8, 18071827.

Milton, E.J., Emery, D.R. and Lawrance, D.J., 2000. A new dual beam technique for precise measurements of spectral reflectance in the field. Proceedings of International Symposium on Remote Sensing of Environment, ERIM, Michigan, USA (CD ROM).

Milton, E.J. and Goetz, F.H., 1997. Atmospheric influences on field spectroscopy: observed relationships between spectral irradiance and the variance in spectral reflectance. Seventh International Symposium on Physical Measurements and Signatures in Remote Sensing (ISPRS), Courchevel, France, 109-114.

Milton, E.J., Rollin, E.M. and Emery, D.R., 1995. Advances in field spectroscopy. In: Danson, F.M. and Plummer, S.E., eds. Advances in Environmental Remote Sensing, John Wiley \& Sons, Chichester, 9-32. 
Moran, M. S., Bryant, R., Thome, K. J., Ni, W. G., Nouvellon, Y., Gonzalez-Dugo, M. P., Qi, J. and Clarke, T. R., 2001. A refined empirical line approach for reflectance factor retrieval from Landsat-5 TM and Landsat-7 ETM+. Remote Sensing of Environment 78, 71-82.

Price, J. C., 1994. How unique are spectral signatures? Remote Sensing of Environment 49, 181-186.

Richardson, A. J., 1981. Measurement of reflectance factors under daily and intermittent irradiance variations. Applied Optics 20, 3336-3340.

Rollin, E. M., Milton, E. J. and Emery, D. R., 2000. Reflectance panel anisotropy and diffuse radiation - some implications for field spectroscopy. International Journal of Remote Sensing 21, 2799-2810.

Rollin, E. M. and Milton, E. J., 2003. Estimating spectral irradiance from measurements in seven spectral bands. Scales and dynamics in observing the environment, Proceedings of the Annual Conference of the Remote Sensing and Photogrammetry Society, Nottingham, UK, CD-ROM.

Slater, P. N., Biggar, S. F., Holm, R. G., Jackson, R. D., Mao, Y., Moran, M. S., Palmer, J. M. and Yuan, B., 1987. Reflectance- and radiance-based methods for the in-flight absolute calibration of multispectral scanners. Remote Sensing of Environment 22, 11-37. 